\title{
Some Implications of Relative Biomechanical Neck Length in Hominid Femora ${ }^{1}$
}

\author{
MILFORD H. WOLPOFF \\ Department of Anthropology, University of Michigan, Ann Arbor, Michigan 48109
}

\begin{abstract}
KEY WORDS Biomechanical femur neck length . Femur - Sexual dimorphism . Evolution of pelvic inlet . Evolution of cranial capacity
\end{abstract}

\begin{abstract}
Demonstration of a size-based influence on relative biomechanical neck length of the femur predicts relatively longer necks for smaller femurs Fossil hominids through the middle Pleistocene appear to have relatively longer femur necks than expected from this relation, excepting the two small australopithecine females. It is suggested that this variation results from smaller crania at birth in the fossils, and the possibility is raised that australopithecine populations were characterized by marked brain size differences at birth.
\end{abstract}

Biomechanical length of the femoral neck was defined ${ }^{2}$ to be the best, easily reproducible, osteological measure of the distance between the weight bearing point on the femur head and the abductor attachment on the greater trochanter (Lovejoy et al., '73: p. 762). Its length, relative to femur length, is one of the features which most consistently separates australopithecine and living human femora (Lovejoy and Heiple, '72; Lovejoy, '75; Walker, '73; Wolpoff, '76a). It has been suggested that this difference corresponds to the smaller birth canal (or pelvic inlet) in australopithecines relative to total pelvis size (Lovejoy et al., '73). Yet, the fact that most fragmentary australopithecine femora and all of the complete or reconstructable ones are very small, compared to sample means for living humans represented in most comparative collections, suggests that systematic sizebased variation might have to be taken into account for valid comparisons between the australopithecines and living human samples.

The question of whether such size-based variation in biomechanical neck length exists was examined using a sample of femora from the Northeast Ohio Libben Amerind site that had been sexed by pelvic indicators. In a mixed sex sample of 148 individuals, biomechanical neck length was found to be positively and linearly related to morphological (i.e., "in position") bone length; the least squares fitted power function exponent of 0.98 is not signifi- cantly different from 1.0 , and the linear correlation of 0.683 is significant at the 0.001 level. Moreover, the best fitting power curve predicts virtually no difference in relative biomechanical neck length $(100 \times$ biomechanical neck length/morphological femur length) over a range of femur lengths from $250 \mathrm{~mm}(15.5)$ to $500 \mathrm{~mm}(15.3)$.

However, in living humans the relative size of the pelvic inlet differs between males and females; holding total pelvis size constant, the inlet is broader in females (Lovejoy, '75) since it functions as a birth canal. The relatively narrower male pelvic inlet increases the horizontal distance between the abductors and the acetabulum on the innominate, and there should be a corresponding increase in this distance on the femur for the same mechanical relations of the hip musculature to be maintained. Thus, the positive correlation and the magnitude of the linear slope in the Libben sample may be a function of more than just the size difference between males and females. The longer biomechanical necks in the male femora may also respond to the relatively narrow inlet. The effect of both of these

\footnotetext{
${ }^{1}$ Research underlying this study was supported by NSF Grants GS. 33035 and BNS $75-21756$.

${ }^{2}$ Lovejoy, Heiple, and Burstein define the measure as "the right angle distance from the lateral-most point of the greater trochanter to its tangential point of intersection with the most cephalad point of the femur head" (p. 762). The measure is easily taken by laying the proximal portion of a femur on its lateral side with the shaft horizontal, and finding the point of intersection between the head and a vertical ly positioned ruler.
} 
TABLE 1

Data for least squares linear relationship of biomechanical neck length (independent variable) and morphological femur length for pelvically sexed male and female Libben Amerind samples and some fossil hominids (see table 3). Data are in millimeters. Standard errors cannot be calculated because the data are not normal

\begin{tabular}{lccccc}
\hline & $\begin{array}{c}\text { Sample } \\
\text { size }\end{array}$ & Correlation & Significance & Slope & Intercept \\
\hline Libben males & 52 & 0.231 & $<0.05$ & 0.088 & 30.714 \\
Libben females & 46 & 0.421 & $<0.005$ & 0.090 & 25.715 \\
4 middle Pleistocene & & & & & \\
hominids and ER 1481 & 5 & 0.922 & $<0.025$ & 0.087 & 37.077 \\
\hline
\end{tabular}

TABLE 2

Absolute and relative biomechanical neck lengths based on Libben male and female regressions presented in table 1. Data are in millimeters

\begin{tabular}{|c|c|c|c|c|}
\hline \multirow{2}{*}{$\begin{array}{l}\text { Morphological } \\
\text { femur length }\end{array}$} & \multicolumn{2}{|c|}{$\begin{array}{l}\text { Biomechanical neck length } \\
\text { regression estimate }\end{array}$} & \multicolumn{2}{|c|}{$\begin{array}{c}\text { Relative biomechanical } \\
\text { neck length }\end{array}$} \\
\hline & Males & Females & Males & Females \\
\hline 250 & 52.7 & 48.1 & 21.1 & 19.3 \\
\hline 275 & 54.8 & 50.4 & 19.9 & 18.4 \\
\hline 300 & 57.0 & 52.6 & 19.0 & 17.5 \\
\hline 325 & 59.2 & 54.8 & 18.2 & 16.9 \\
\hline 350 & 61.4 & 57.1 & 17.6 & 16.3 \\
\hline 375 & 63.6 & 59.3 & 17.0 & 15.9 \\
\hline 400 & 65.8 & 61.6 & 16.4 & 15.4 \\
\hline 425 & 68.0 & 63.8 & 16.0 & 15.1 \\
\hline 450 & 70.2 & 66.0 & 15.6 & 14.7 \\
\hline 475 & 72.4 & 68.3 & 15.2 & 14.1 \\
\hline 500 & 74.6 & 70.5 & 14.9 & 14.1 \\
\hline
\end{tabular}

variables combined is to elevate the magnitude of positive relationship observed between biomechanical neck length and femur length by admitting a second contributing influence.

The degree to which the size-based relation is masked by the sex difference can be examined by analyzing the relation within each sex. A least squares regression was used to predict biomechanical neck length from morphological femur length in the Libben sample (table 1). A linear relation was indicated by the 0.98 exponent of the power curve. The correlations and the magnitude of the linear slope are less than in the sample of both sexes although the correlations remain significant. That the slopes for males and females are virtually identical suggests the systematic variation within each sex is subject to the same biological scaling process. However, the low correlations indicate that other non-systematic factors also influence the observed variation. Nonetheless, a size-based component to biomechanical neck length is demonstrated by these data.

The linear slope of the combined-sex sample was 0.151 . The fact that slopes for the singlesex samples are markedly less leads to a rather different relation of relative biomechanical neck length and femur length than the virtual independence of these variables in the combined sex sample. However, the relation within each sex is a better estimate of the influence of femur length alone on relative biomechanical neck length. When the regression formulae are used to predict absolute and relative biomechanical neck lengths for femurs varying over the expected australopithecine range (table 2), the marked influence on relative biomechanical neck length can be observed. There is a notable negative relation between relative neck length and femur length; the smaller the femur, the relatively longer the biomechanical neck length. Overwhelming evidence indicates that the australopithecine pelvic-femoral complex was completely modern in all functional aspects that can be ascertained from the osteological morphology (Lovejoy et al., '73; Lovejoy, '75). Thus, a modern model should be applicable to the femoral mechanics. Such a model suggests that since the complete or reconstructable aus- 
TABLE 3

Actual and predicted relative biomechanical neck lengths (using the table 1 formulae) for earlier fossil hominids. Measurements are in millimeters

\begin{tabular}{|c|c|c|c|c|}
\hline \multirow[b]{3}{*}{$\begin{array}{l}\text { Pliocene/Lower } \\
\text { Pleistocene }\end{array}$} & \multirow[b]{3}{*}{$\begin{array}{l}\text { Morphological } \\
\text { length }\end{array}$} & \multicolumn{3}{|c|}{ Relative biomechanical neck length } \\
\hline & & \multirow[b]{2}{*}{ Actual } & \multicolumn{2}{|c|}{ Predicted } \\
\hline & & & $\begin{array}{c}\text { Male } \\
\text { prediction }\end{array}$ & $\begin{array}{l}\text { Female } \\
\text { prediction }\end{array}$ \\
\hline AI. $288^{\prime}$ & 280 & 16.8 & 19.7 & 18.2 \\
\hline STS $14^{2}$ & 285 & 18.2 & 19.5 & 18.0 \\
\hline ER $1481^{3}$ & 390 & 18.2 & 16.6 & 15.6 \\
\hline $\operatorname{ER~} 1472^{3}$ & 400 & $>16.3$ & 16.4 & 15.4 \\
\hline \multicolumn{5}{|l|}{ Middle Pleistocene } \\
\hline $\operatorname{ER~} 999^{4}$ & 470 & $>16.4$ & 15.3 & 14.5 \\
\hline Broken Hill $689^{5}$ & 456 & 16.9 & 15.5 & 14.6 \\
\hline $907^{5}$ & 465 & 17.0 & 15.4 & 14.5 \\
\hline Trinil $1^{3}$ & 455 & 16.5 & 15.6 & 14.7 \\
\hline
\end{tabular}

${ }^{1}$ Neck length provided by Johanson, morphological length from Johanson and Taieb (76)

${ }^{2}$ From the Lovejoy and Heiple ('TO) length determination to the head midpoint, adding the superior portion of the head.

${ }^{3}$ Measured by the Author; the bone is complete or virtually complete.

' Estimated by the Author; this measurement was guggested as the minimum length by Day and Leakey (74).

${ }^{5}$ Neither bone is complete. Length determinations based on predictions following procedures published by Steele and McKern ('69).

tralopithecine femurs are small, the fact that these are characterized by relatively great biomechanical neck lengths is, in part, the result of their size.

One could estimate the influence of size on relative biomechanical neck length for these specimens by comparing actual relative length to that predicted by the Libben formulae. Attempting this leads to two unexpected results (table 3 ). First, the small specimens have relative neck lengths as small as or smaller than predicted. Both STS 14 and AL 288 are females, and their actual and predicted values using the female formula are similar. Second, excepting the damaged Turkana specimen ER 1472 which only allows a "greater than" estimate, the larger specimens have relative neck lengths much greater than predicted by either formula, and moreover large relative neck size extends at least through the middle Pleistocene.

Do these data show that the smaller australopithecines simply represent the human condition expressed at their diminutive body size? To some extent this may be true; it is possible to find small human femora with most or all of the characteristics found in the australopithecines (fig. 1). Unfortunately, no systematic analysis of biomechanical neck length exists for a very small human population. Moreover, one must also contend with the presence of relatively long biomechanical neck length in larger australopithecines and large later hominids, and the fact that a regression analysis based on the larger early specimens predicts even relatively longer necks for the small females. The problem is that even if the specific human regression should not be applied to "predict" the australopithecine female values, the relationship of relatively longer necks in smaller individuals should hold and the females do not fit this prediction.

To review, analysis of separate sexes within a single biological population of living humans reveals a low level but significant linear relation between biomechanical neck length and femur length. The effect of this relation on the relative length of the femur neck is to predict that relatively longer necks will be expressed with smaller femur size. Comparison of the expected to the actual relative neck length for hominid femora through the middle Pleistocene shows that all of the larger femora have relatively longer necks than expected, while the two small australopithecine females have the relative neck length that is predicted from the human regression, if not shorter.

The interpretation of the larger lower Pleistocene specimens and the middle Pleistocene specimens seem clear; these femora have relatively long biomechanical neck lengths. Moreaver, a linear regression based on these five specimens has the same slope as the Libben samples (table 1) and differs only in the intercept value. While five specimens are too few for firm conclusions, it would seem that the same size dependence of 


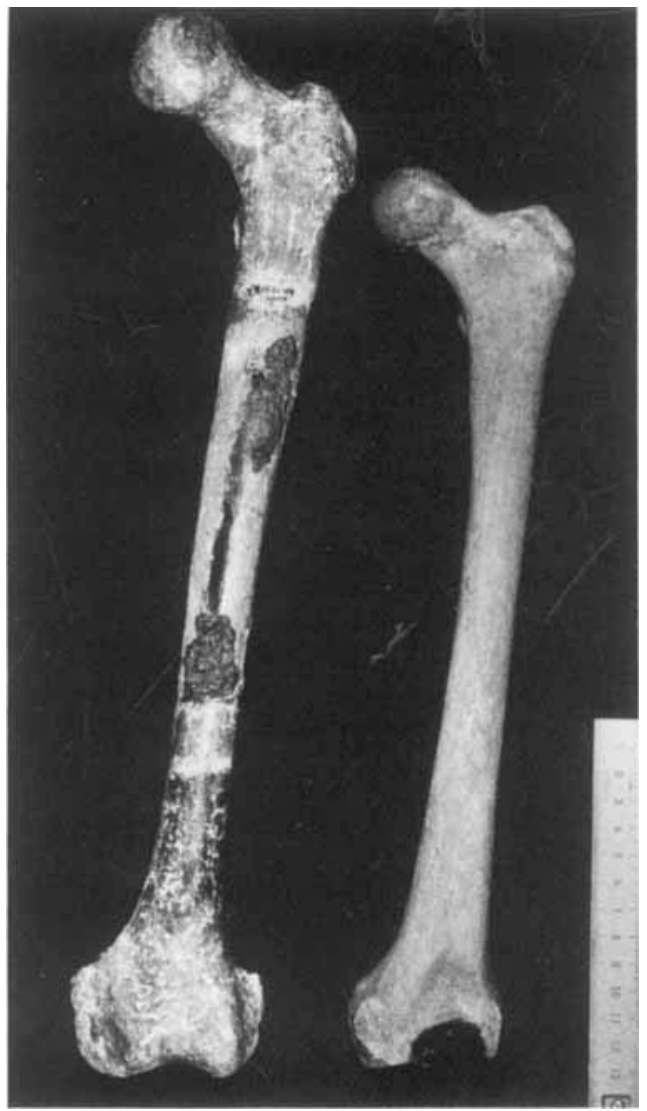

Fig. 1 Comparison of a small modern human femur with a relatively long neck (right) and a cast of the Turkana australopithecine ER 1481. The human was provided by the University of Michigan Medical School.

biomechanical neck length as in living humans is expressed by these data, and that the magnitude of relative neck length only differs from humans in the predicted values because of the different intercepts. The most reasonable explanation is based on the functional interpretation of biomechanical neck length; these hominids are characterized by relatively smaller brain size at birth and therefore narrower pelvic inlets and a correspondingly greater horizontal distance between the acetabulum and the abductor attachment.

It is the two small australopithecine females that are problematic, since the relative lengths of their femoral necks are not as large as one would expect from the larger sized early hominid femora, based on this regression analysis. The size of the correlations provides the possibility that the variation may be acciden- tal; only larger sample sizes can resolve this. However, the fact that the two known females are similar ${ }^{3}$ lends credence to the idea that they reflect the normal australopithecine female condition. If this is taken as a working hypothesis, what are the implications?

It seems to me that one explanation could lie in the hypothesis that these small females were members of populations in which much larger brained individuals were regularly born. Consequently, their birth canal size was under selection to allow heads to pass through that greatly exceeded the capacity at birth expected for the very small specimens. Leutenegger ('72) reached exactly the same conclusion based on a direct analysis of the STS 14 pelvis, demonstrating that the inlet was much larger than necessary to give birth to individuals with the expected capacity of STS 14sized hominids. The same conclusion applies to expected brain size at birth for the known Sterkfontein adults. The fact that no larger brained specimens are known from Sterkfontein led him to conclude that births were generally easy, and that selection other than cranial size at birth influenced the dimensions of the pelvic inlet.

The fact is that there are larger brained australopithecine specimens. However, these were recovered in East Africa (ER 1470, 1590, 3732 ) and are generally thought to be populationally, if not taxonomically distinct, because of their larger brain size. The contention that the small australopithecine females could have given birth to specimens with these larger adult capacities may be irrelevant in view of the fact that no larger brained specimens have yet been found in the Afar, Sterkfontein, or Swartkrans excavations. Yet, there are some hints that the absence of such specimens may be accidental and not a true reflection of the biological variation. These are mainly the large dimensions of Swartkrans crania such as SK 46 (Wolpoff, '74), and the fact that the largest Sterkfontein capacity occurs in a female cranium (STS 5, Wolpoff, '76b). The expectation of even a low magnitude of sexual dimorphism would predict larger male capacities at Sterkfontein, and

\footnotetext{
Femur length in both specimens is reconstructed. However, the methods of reconstruction wre quite different. The Sterkfontein female reconstruction is based on the use of the pelvic dimensions and the application of the average australopithecine bycondylar angle to the existing proximal fragment (Lovejoy and Heiple, '70) while the Afar female reconstruction is based on a lower midshaft fit of the existing portions and an estimate of the amount of distal surface crush. ing IJohanson and Taieh, '76). That different estimation procedures provide the same results is confirmatory
} 
there is reason to believe that the actual amount of body size dimorphism was marked. If body weight dimorphism approached the $100 \%$ average value predicted from specimens sexed by canine size (Wolpoff, '76b), there is every reason to predict that males with the cranial size of the large East African specimens could have born into australopithecine populations with the characteristics of the Sterkfontein or Afar hominids. Presumably, marked adult brain size dimorphism would be reflected by brain size differences at birth.

While this evidence is coincidental, the fact remains that it provides an explanation for the otherwise anomalous relative femur neck lengths of the two australopithecine females. The validity of this hypothesis can only be determined with the recovery of more specimens.

In sum, it would appear that relatively long biomechanical neck length characterizes much of Pleistocene hominid evolution, and that this feature is unlikely to be of taxonomic value prior to the Upper Pleistocene. While the small female australopithecine femur necks are relatively long, they are not as long as expected from the larger sized early hominid femurs or from expectations of cranial size at birth for small australopithecines. One explanation for this anomaly is the hypothesis that the populations they represent were characterized by marked sexual dimorphism in body size, and a correspondingly large range of cranial size at birth; it is the maximum of this range that would provide the source of selection for pelvic inlet size. On the other hand, the relative biomechanical neck length for these two specimens may be an artifact of sampling; only future discoveries can resolve this. I believe the sample sizes are large enough to indicate clearly only that relative biomechanical neck length in fossil and living hominids responds to the same size-based relationships which predict relatively longer femur necks in smaller individuals, and that the differences in actual magnitudes between living and fossil hominids correspond to selection acting on the degree to which this relationship is expressed (i.e., the intercept rather than the slope), reflecting the gradual expansion of adult brain size and therefore of brain size at birth.

\section{ACKNOWLEDGMENTS}

I thank C. O. Lovejoy for kindly providing measurements of the Libben femora, D. C. Johanson for providing the neck length of AL 288 , and the individuals and institutions allowing me to examine the original fossil hominid specimens; R. E. F. Leakey of the National Museum of Kenya, C. K. Brain of the Transvaal Museum, and C. Stringer of the British Museum.

\section{LITERATURE CITED}

Day, M. H., and R. E. F. Leakey 1974 New evidence for the genus Homo from East Rudolf, Kenya, III. Am. J. Phys. Anthrop., 41: $367-380$.

Johanson, D. C., and M. Taieb 1976 Plio-Pleistocene hominid discoveries in Hadar, Ethiopia. Nature, 260: 293-297.

Leutenegger, W. 1972 New born size and pelvic dimensions of Australopithecus. Nature, 240: 568-569.

Lovejoy, C. O. 1975 Biomechanical perspectives on the lower limb of early hominids. In: Primate Functional Morphology and Evolution. R. Tuttle, ed. Mouton: The Hague, pp. 291-326

Lovejoy, C. O., and K. G. Heiple 1970 A reconstruction of the femur of Australopithecus africanus. Am. J. Phys. Anthrop., 32: 33-40.

_ 1972 Proximal femoral anatomy of Australo. pithecus. Nature, 225: 175-176.

Lovejoy, C. O., K. G. Heiple and A. H. Burstein 1973 The gait of Australopithecus. Am. J. Phys. Anthrop., 38: 757.780

Steele, D. C., and T. W. McKern 1969 A method for assessment of maximum longbone length and living stature from fragmentary long bones. Am. J. Phys. Anthrop., 31: 215-227.

Walker, A. C. 1973 New Australopithecus femora from East Rudolf, Kenya. J. Hum. Evol., 2: 215-227.

Wolpoff, M. H. 1974 The evidence for two australopithecine lineages in South Africa. Yrb. Phys. Anthrop., 17: 113-139.

1976a Fossil hominid femora. Nature, 264: $812-813$

$1976 \mathrm{~b}$ Some aspects of the evolution of early hominid sexual dimorphism. Cur. Anthrop., 17: 579.606. 